\title{
Survival benefit of lung transplantation compared with medical management and pulmonary rehabilitation for patients with end-stage COPD
}

Irina Timofte 1 , Marniker Wijesinha², Roumen Vesselinov², June Kim', Robert Reed ${ }^{1}$, Pablo G. Sanchez ${ }^{3}$, Nicholas Ladikos ${ }^{4}$, Si Pham ${ }^{5}$, Zachary Kon ${ }^{6}$, Keshava Rajagopal ${ }^{7}$, Steven M. Scharf ${ }^{1}$, Robert Wise (10) ${ }^{8}$, Alice L. Sternberg ${ }^{9}$, David Kaczorowski ${ }^{10}$, Bartley Griffith ${ }^{10}$, Michael Terrin ${ }^{2}$ and Aldo lacono ${ }^{11}$

Affiliations: ${ }^{1}$ Dept of Medicine, University of Maryland Medical Center, Baltimore, MD, USA. ${ }^{2}$ Dept of Epidemiology and Public Health, University of Maryland Medical Center, Baltimore, MD, USA. ${ }^{3}$ Dept of Cardio Thoracic Surgery, University of Pittsburgh, Pittsburgh, PA, USA. ${ }^{4}$ Dept of Pharmacy, Suburban Hospital/Johns Hopkins Medicine, Bethesda, MD, USA. ${ }^{5}$ Dept of Cardio Thoracic Surgery, Mayo Clinic Florida, Jacksonville, FL, USA. ' $D e p t$ of Thoracic Surgery, New York University, New York, NY, USA. ${ }^{7}$ Dept of Cardio Thoracic Surgery, University of Texas Health Science Center at Houston, Houston, TX, USA. ${ }^{8}$ Dept of Medicine, Johns Hopkins University School of Medicine, Baltimore, MD, USA. ${ }^{9}$ Dept of Epidemiology, Johns Hopkins Bloomberg School of Public Health, Baltimore, MD, USA. ${ }^{10}$ Dept of Cardio Thoracic Surgery, University of Maryland Medical Center, Baltimore, MD, USA. ${ }^{11}$ R. Adams Cowley Shock Trauma Center, University of Maryland Medical Center, Baltimore, MD, USA

Correspondence: Irina Timofte, Dept of Medicine, University of Maryland Medical Center, 110 S. Paca St, 2nd Floor, Baltimore, MD 21201, USA. E-mail: IrTimofteaSOM.umaryland.edu

\section{ABSTRACT}

Background: COPD patients account for a large proportion of lung transplants; lung transplantation survival benefit for COPD patients is not well established.

Methods: We identified 4521 COPD patients in the United Network for Organ Sharing (UNOS) dataset transplanted from May 2005 to August 2016, and 604 patients assigned to receive pulmonary rehabilitation and medical management in the National Emphysema Treatment Trial (NETT). After trimming the populations for NETT eligibility criteria and data completeness, 1337 UNOS and 596 NETT patients remained. Kaplan-Meier estimates of transplant-free survival from transplantation for UNOS, and NETT randomisation, were compared between propensity score-matched UNOS $(n=401)$ and NETT $(n=262)$ patients.

Results: In propensity-matched analyses, transplanted patients had better survival compared to medically managed patients in NETT ( $\mathrm{p}=0.003)$. Stratifying on 6 min walk distance $(6 \mathrm{MWD})$ and $\mathrm{FEV}_{1}$, UNOS patients with $6 \mathrm{MWD}<1000 \mathrm{ft}(\sim 300 \mathrm{~m})$ or $\mathrm{FEV}_{1}<20 \%$ of predicted had better survival than NETT counterparts (median survival 5.0 years UNOS versus 3.4 years NETT; log-rank $\mathrm{p}<0.0001$ ), while UNOS patients with $6 \mathrm{MWD} \geqslant 1000 \mathrm{ft}(\sim 300 \mathrm{~m})$ and $\mathrm{FEV}_{1} \geqslant 20 \%$ had similar survival to NETT counterparts (median survival, 5.4 years UNOS versus 4.9 years NETT; log-rank $\mathrm{p}=0.73$ ), interaction $\mathrm{p}=0.01$.

Conclusions: Overall survival is better for matched lung transplant patients compared with medical management alone. Patients who derive maximum benefit are those with $6 \mathrm{MWD}<1000 \mathrm{ft}(\sim 300 \mathrm{~m})$ or FEV $_{1}$ $<20 \%$ of predicted, compared with pulmonary rehabilitation and medical management.

@ERSpublications

Lung transplantation offers a survival benefit for COPD patients with $6 \mathrm{MWD}<1000 \mathrm{ft}$ $(\sim 300 \mathrm{~m})$ or $\mathrm{FEV}_{1}<20 \%$ of predicted compared to pulmonary rehabilitation and medical therapy. 6MWD and $\mathrm{FEV}_{1}$ should be considered in the transplant patient selection process. http://bit.ly/2SlkTIo

Cite this article as: Timofte I, Wijesinha M, Vesselinov R, et al. Survival benefit of lung transplantation compared with medical management and pulmonary rehabilitation for patients with end-stage COPD. ERJ Open Res 2020; 6: 00177-2019 [https://doi.org/10.1183/23120541.00177-2019].

Received: 13 Oct 2019 | Accepted after revision: 6 Feb 2020

Copyright $\odot$ ERS 2020. This article is open access and distributed under the terms of the Creative Commons Attribution Non-Commercial Licence 4.0. 


\section{Introduction}

Lung transplantation is the final therapeutic option for patients with end-stage lung disease. COPD has been the most frequent underlying disease for both single (44\% of all single lung transplants) and double (32\% of all double lung transplants) transplant recipients from 1995 to 2016 [1].

Despite recent improvements in early post-operative outcomes, the median survival time following lung transplantation is approximately 5-6 years. In contrast with other lung diseases, e.g. idiopathic pulmonary fibrosis and pulmonary arterial hypertension, in which lung transplantation is believed to prolong life, the survival benefit is controversial for COPD because advanced-stage COPD outcomes using medical management alone are better than those of other end-stage lung diseases [2-6]. Despite advances in treatment, COPD mortality and prognosis have not changed appreciably in the last three decades. COPD continues to be the fourth most frequent cause of death worldwide [7-10].

A forced expiratory volume in $1 \mathrm{~s}\left(\mathrm{FEV}_{1}\right)<30 \%$ of predicted was associated with survival rates of $65 \%$ and $30 \%$ at 2 and 5 years, respectively [11-13], and $\mathrm{FEV}_{1}$ below $30 \%$ was considered to be a threshold for lung transplant evaluation. Objective measurements like cardiopulmonary exercise test results or 6-min walk distance $(6 \mathrm{MWD})$ were demonstrated to be consistent predictors of mortality $[14,15]$. In an attempt to improve prediction of survival, the BODE index including body mass index (BMI), obstruction, dyspnoea and exercise capacity was developed by CeLLi et al. [16] in 2004.

Lung allocation scores (LAS) were implemented in May 2005 [17]. The models for survival after lung transplantation and wait list survival probability were combined to form a model in which the expected benefit of the transplant was calculated as the difference between predicted post-transplant survival and wait list survival [18]. The National Emphysema Treatment Trial (NETT) elucidated the risks and benefits of lung volume reduction surgery (LVRS) proposed as a therapy for advanced COPD in 2003 [19].

Our study compares COPD patient survival after lung transplantation with the survival of an independent series of severe emphysema patients who received only medical management (the control arm of NETT). We hypothesised that patients with severe COPD attain a survival benefit after lung transplantation and that parameters assessing the severity of disease, such as 6-min walk distance (6 MWD) and forced expiratory volume in $1 \mathrm{~s}\left(\mathrm{FEV}_{1}\right)$, are determinants of transplant benefit.

\section{Material and methods}

The University of Maryland Baltimore Institutional Review Board granted the study an exemption (HP-00068606) from informed consent for review of data from UNOS (the United Network for Organ Sharing) and NETT.

We present patient characteristics for the following three groups obtained from the UNOS and NETT data files: UNOS patients listed for lung transplantation in the LAS era, UNOS patients transplanted in the LAS era and NETT patients randomised to the control arm of the trial (to receive only pulmonary rehabilitation and standard medical therapy).

For continuous variables, medians and interquartile ranges were compared with Wilcoxon rank-sum tests, as statistical tests for normality (including Shapiro-Wilk and Kolmogorov-Smirnov) rejected normality of distributions for several variables. Categorical variables, frequency distributions were analysed using chi-squared tests. We compared baseline characteristics of the UNOS transplanted patients and NETT control patients; we did not make a separate comparison of UNOS listed and NETT rehabilitation group patients' baseline characteristics because UNOS listed and UNOS transplanted patients had a large overlap and were very similar in the baseline characteristics we assessed.

We first compared transplant-free survival between all UNOS listed patients (censoring transplanted patients at the time of surgery) and NETT control patients. Our primary analyses compared post-transplant survival for UNOS transplanted patients to survival after randomisation for NETT control patients. Re-transplantation for UNOS patients and transplantation following randomisation for NETT patients were taken to be treatment failures. In UNOS, deaths of the study participants were ascertained via the US Social Security Death Index. Patients were followed for a maximum of 10 years after transplantation or randomisation and were censored if alive and free of subsequent transplantation at the end of follow-up. NETT patients underwent complete evaluations at 6 months, 12 months, and yearly thereafter.

A propensity score was computed for each patient in the UNOS COPD and NETT patient population, using a logistic regression model that included the following parameters, selected based on clinical relevance and literature review [11-16]: age, sex, percent predicted of $\mathrm{FEV}_{1}$, percent predicted of forced vital capacity (FVC), $6 \mathrm{MWD}$, oxygen requirements, carbon dioxide tension $\left(\mathrm{P}_{\mathrm{CO}_{2}}\right)$ and body mass index (BMI). UNOS patients were excluded if they had values outside ranges based on eligibility criteria for NETT and plausibility for COPD transplant patients: $18 \leqslant$ age $\leqslant 80$ years, $5 \leqslant \mathrm{FEV}_{1} \leqslant 45 \%$ predicted, 
$10 \leqslant$ FVC $\leqslant 100 \%$ predicted, $6 \mathrm{MWD} \geqslant 140 \mathrm{~m} \quad(459 \mathrm{ft}),. 0 \leqslant \mathrm{O}_{2}$ requirements $\leqslant 6 \mathrm{~L}$ per min., $25 \leqslant$ Partial pressure of carbon dioxide $\left(P_{\mathrm{aCO}_{2}}\right) \leqslant 60 \mathrm{mmHg}$, mean pulmonary artery pressure $(\mathrm{PAP}) \leqslant 35 \mathrm{mmHg}$, and $15 \leqslant \mathrm{BMI} \leqslant 31.1 \mathrm{~kg} \cdot \mathrm{m}^{-2}$ for females and $32.2 \mathrm{~kg} \cdot \mathrm{m}^{-2}$ for males. A greedy matching algorithm implemented via the gmatch SAS macro was used to match patients between NETT and UNOS based on the propensity score, with one-to-many matching.

The log-rank test was used for survival analyses, and the Renyi test when survival curves crossed. Survival comparisons between UNOS transplanted and NETT patients were repeated after stratifying patients by $6 \mathrm{MWD}$ and $\mathrm{FEV}_{1}$, and post-transplant survival was compared between the full populations of "more severe" ( $6 \mathrm{MWD}<1000 \mathrm{ft}(\sim 300 \mathrm{~m})$ or $\mathrm{FEV}_{1}<20 \%$ predicted) and "less severe" (6 MWD $\geqslant 1000 \mathrm{ft}(\sim 300$ $\mathrm{m})$ and $\mathrm{FEV}_{1} \geqslant 20 \%$ predicted) transplanted COPD patients in UNOS. The decision to use cut-offs of $20 \%$ for $\mathrm{FEV}_{1}$ and $1000 \mathrm{ft}(\sim 300 \mathrm{~m})$ for $6 \mathrm{MWD}$ was based on clinical experience. The most recent ISHLT consensus document recommend a $\mathrm{FEV}_{1}$ less than $15 \%$ to $20 \%$ predicted as criteria for lung transplant listing [20]. Similarly, a 6 MWD less than $1000 \mathrm{ft}(\sim 300 \mathrm{~m})$ was associated with increased mortality in 1-year experience [21].

Analyses were conducted with SAS Software, version 9.4, and $\mathrm{p}<0.05$ (two-tailed) statistically significant.

\section{Results}

We identified 4521 COPD patients in the UNOS dataset who received a transplant between May 2005 and August 2016; 5938 COPD patients were listed for transplantation in this same era. 604 patients were randomised to pulmonary rehabilitation and medical treatment in the NETT between January 1998 and July 2002. Demographic and clinical characteristics for the three populations (UNOS listed, UNOS transplanted and NETT control) are shown in table 1.

A Kaplan-Meier plot comparing transplant-free survival between the UNOS listed (censoring transplanted patients at the time of surgery) and NETT control populations is shown in figure 1. Median survival

TABLE 1 Patient characteristics at baseline

\begin{tabular}{|c|c|c|c|c|c|c|c|}
\hline & UNOS listed & $\begin{array}{l}\text { Unmatched Patients } \\
\text { UNOS transplanted }\end{array}$ & NETT control & p-value ${ }^{\pi}$ & $\begin{array}{l}\text { Matched Patients } \\
\text { UNOS transplanted }\end{array}$ & NETT control3 & p-value \\
\hline Subjects n & 5938 & 4521 & 604 & & 401 & 262 & \\
\hline Age years & $61(56-64)$ & $61(57-65)$ & $67(64-71)$ & $<0.0001$ & $64(61-67)$ & $65(61-68)$ & 0.02 \\
\hline$\geqslant 65$ & $1445(24)$ & $1287(28)$ & $432(72)$ & $<0.0001$ & $199(50)$ & $152(58)$ & 0.04 \\
\hline Female sex & $3043(51)$ & 2182 (48) & $219(36)$ & $<0.0001$ & $177(44)$ & 109 (42) & 0.52 \\
\hline Non-white & $476(8)$ & $349(8)$ & $35(6)$ & & $17(4)$ & $16(6)$ & \\
\hline $\mathrm{BMI} \mathrm{kg} \cdot \mathrm{m}^{-2}$ & $24(21-28)^{\#}$ & $24(21-27)^{\#}$ & $25(22-27)^{\#}$ & 0.12 & $25(22-27)$ & $24(21-28)$ & 0.76 \\
\hline \multicolumn{8}{|l|}{ Disease severity } \\
\hline FVC \% pred & $54(43-65)^{\#}$ & $52(41-64)^{\#}$ & $58(48-68)^{\#}$ & $<0.0001$ & $55(47-65)$ & $55(45-65)$ & 0.92 \\
\hline $\mathrm{FEV}_{1} \%$ pred & $20(16-25)^{\#}$ & $20(16-25)^{\#}$ & $24(20-29)^{\#}$ & $<0.0001$ & $21(18-25)$ & $22(18-26)$ & 0.10 \\
\hline $6 \mathrm{MWD} \mathrm{ft}$ & $760(497-984)^{\#}$ & $770(504-998)^{\#}$ & $1229(990-1413)^{\#}$ & $<0.0001$ & $1000(810-1191)$ & $1065(860-1280)$ & 0.01 \\
\hline $\begin{array}{l}\mathrm{O}_{2} \text { requirements at } \\
\text { rest } \mathrm{L}\end{array}$ & $3(2-3)^{\#}$ & $3(2-4)^{\#}$ & $1(0-2)$ & $<0.0001$ & $2(2-3)$ & $2(2-2)$ & 0.04 \\
\hline$P_{\mathrm{CO}_{2}} \mathrm{mmHg}$ & $47(42-54)^{\#}$ & $49(43-58)^{\#}$ & $43(39-46)$ & $<0.0001$ & $45(40-50)$ & $44(40-49)$ & 0.49 \\
\hline $\begin{array}{c}\text { Mean PAP } \geqslant 35 \\
m m H g\end{array}$ & $555(10)^{\#}$ & $455(11)^{\#}$ & $0(0)^{+}$ & & $0(0)^{+}$ & $0(0)^{+}$ & \\
\hline \multicolumn{8}{|c|}{ Transplant characteristics } \\
\hline \multicolumn{8}{|c|}{ Type of lung transplant } \\
\hline Single & NA & $1756(39)^{\#}$ & NA & & $183(46)$ & NA & \\
\hline Double & NA & $2764(61)^{\#}$ & NA & & $218(54)$ & NA & \\
\hline
\end{tabular}

Data are presented as median (interquartile range) or $\mathrm{n}(\%)$, unless otherwise stated. UNOS: United Network for Organ Sharing; NETT: National Emphysema Treatment Trial; BMI: body mass index; FVC: forced vital capacity; FEV 1 : forced expiratory volume in $1 \mathrm{~s}$; 6MWD: 6-min walk distance; $P_{\mathrm{CO}_{2}}$ : carbon dioxide tension; PAP: pulmonary arterial pressure. NA: not applicable. ${ }^{\#}$ : At least one patient was missing data on this variable, so statistics are based on patients with available data; " : p-value is for the comparison of the UNOS transplanted and NETT control groups; ${ }^{+}$: mean PAP $\geqslant 35$ was an exclusion criterion for NETT, so prior to matching, we excluded patients with PAP $\geqslant 35$. 


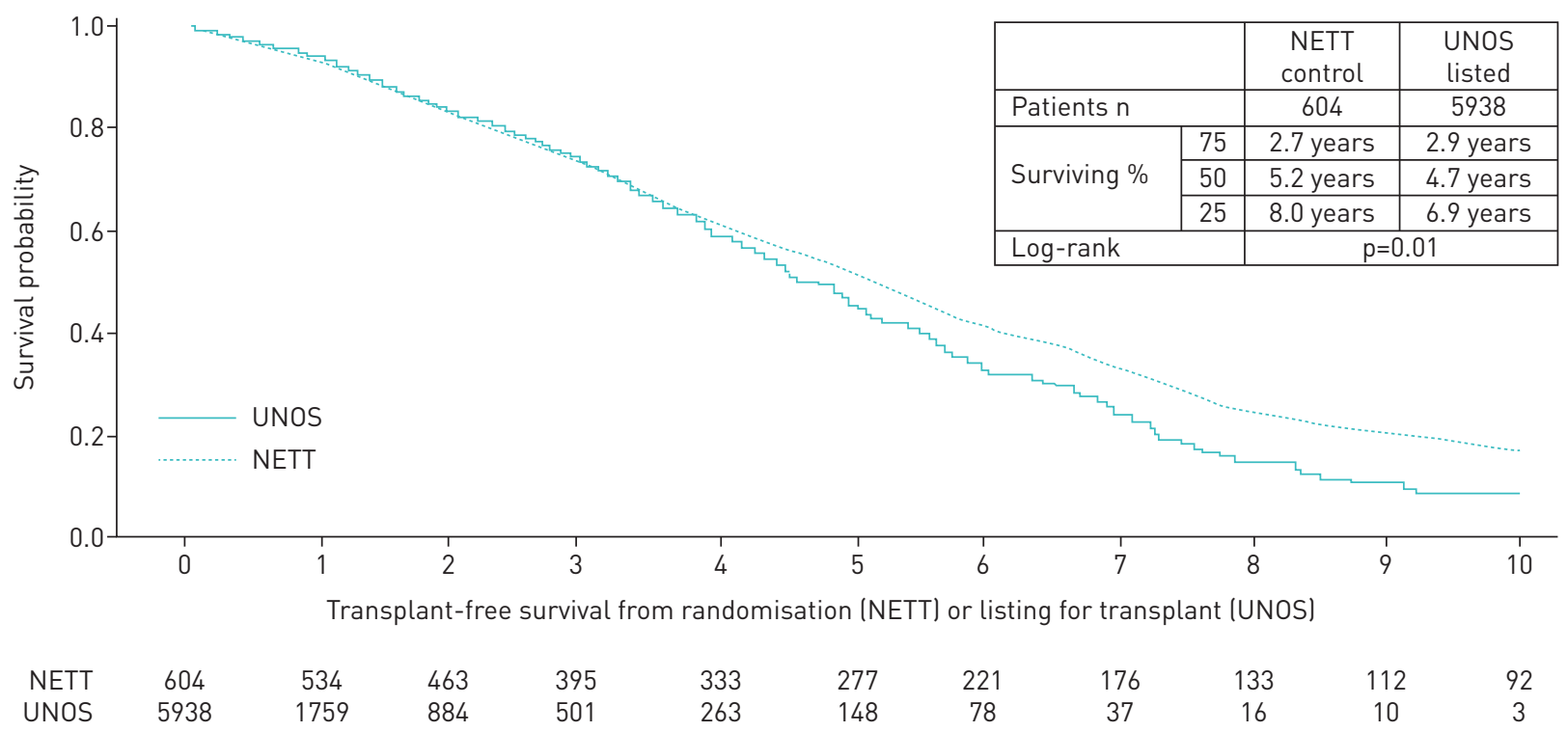

FIGURE 1 Kaplan-Meier plot of transplant-free survival for United Network for Organ Sharing (UNOS) listed and National Emphysema Treatment Trial (NETT) patients.

without transplantation was 5.2 years in the NETT population and 4.7 years in the UNOS listed population (log rank $\mathrm{p}=0.01)$.

After excluding patients with missing data on one or more of the variables to be used for propensity score matching, excluding patients whose values on at least one of these variables were inconsistent with NETT eligibility criteria or untenable for a COPD transplant patient, and matching the remaining UNOS transplanted and NETT control patients, there were 262 patients from NETT and 401 patients from UNOS. Figure 2 contains a Kaplan-Meier plot comparing survival between the matched UNOS transplanted and NETT control patients. The median (IQR) survival free of subsequent transplantation was 4.0 years (2.2-6.6 years) in NETT, compared 5.1 years (1.9-10.1 years) in UNOS (log rank $\mathrm{p}=0.003$ ). In the first 2 years after transplantation or randomisation, the probability of survival was similar for UNOS patients and NETT patients, ( $74 \%$ versus $77 \%$; $\mathrm{p}=0.28$ ). Around 2.5 years the survival curves cross. Since the survival crossed, the Renyi test was performed for comparison of survival between the two groups $(\mathrm{p}<0.0001)$.

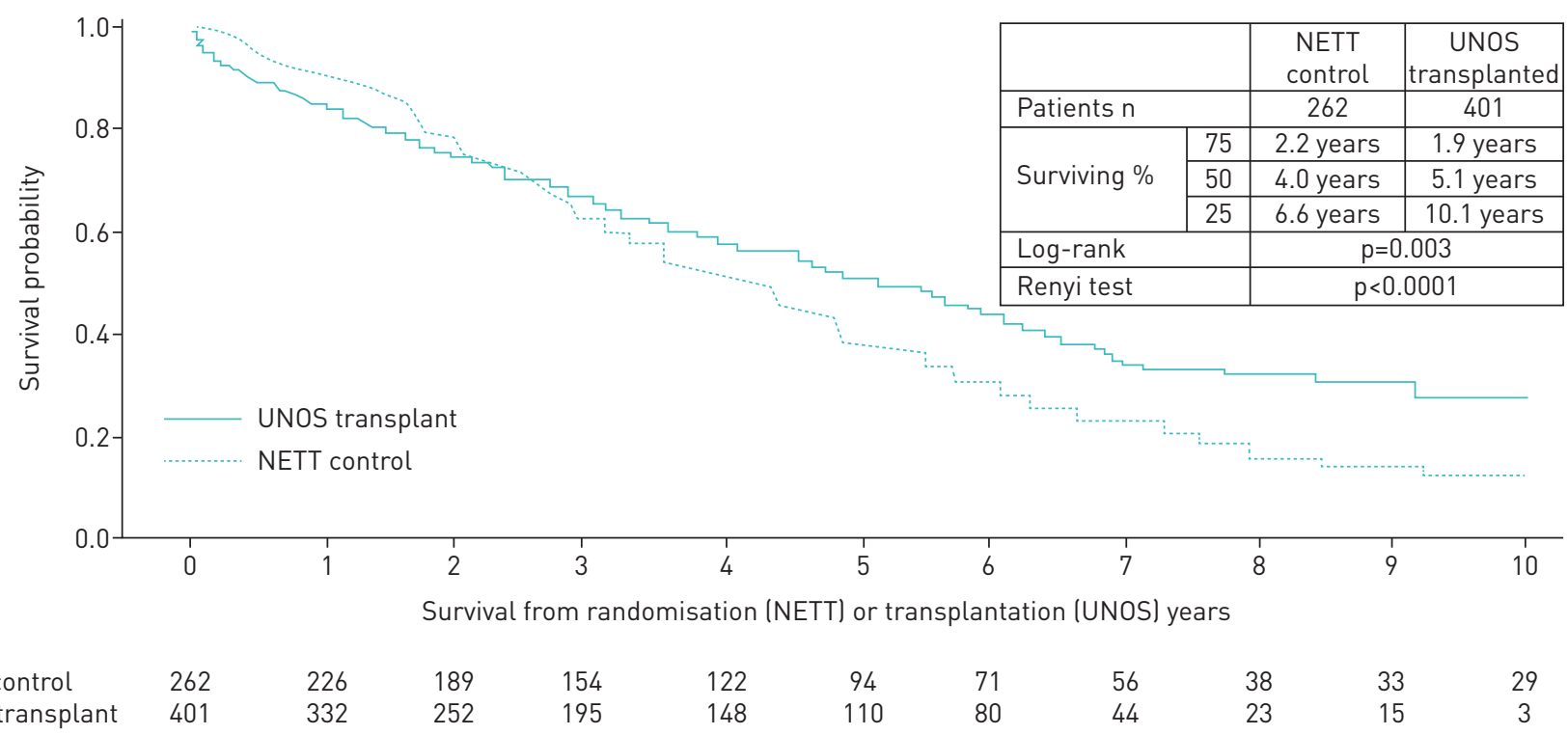

FIGURE 2 Kaplan-Meier plot of survival curves for propensity-matched United Network for Organ Sharing (UNOS) transplant patients and National Emphysema Treatment Trial (NETT) patients. 
The crossing NETT and UNOS survival curves suggest the possibility of heterogeneity in the benefit of transplant (e.g. a trade off of perioperative mortality against a long-term survival improvement). When we stratified patients according to disease severity as indicated by $6 \mathrm{MWD}$ and $\mathrm{FEV}_{1}$, out of the $4496 \mathrm{UNOS}$ transplanted patients who had $6 \mathrm{MWD}$ and $\mathrm{FEV}_{1}$ data available, $89 \%$ (4004) were in the more severe stratum, and $11 \%$ (496) were in the less severe stratum.

Within each disease severity stratum, a Kaplan-Meier plot comparing survival between matched UNOS transplanted and NETT patients is shown in figure 3. In the more severe stratum, median (IQR) survival among the matched patients was 5.0 years (1.9-10.1 years) for UNOS transplanted patients and 3.4 years (1.9-5.5 years) for NETT patients; log-rank $\mathrm{p}<0.0001$ and Renyi $\mathrm{p}<0.0001$. In the less severe stratum, median survival was 5.4 years (1.8-9.2 years) for UNOS, and 4.9 years (2.6-7.9 years) for NETT; log-rank $\mathrm{p}=0.73$, Renyi $\mathrm{p}=0.61$. The test for heterogeneity between these two strata was significant at $\mathrm{p}=0.01$.

Survival percentages at each year were calculated (fig. 3). For patients with a $\mathrm{FEV}_{1} \leqslant 20 \%$ predicted and $6 \mathrm{MWD} \leqslant 1000 \mathrm{ft}(\sim 300 \mathrm{~m})$, a survival benefit of transplantation was apparent after 2 years, while for patients with $\mathrm{FEV}_{1}>20 \%$ predicted and $6 \mathrm{MWD}>1000 \mathrm{ft}(\sim 300 \mathrm{~m})$, transplantation did not appear to confer a survival advantage.

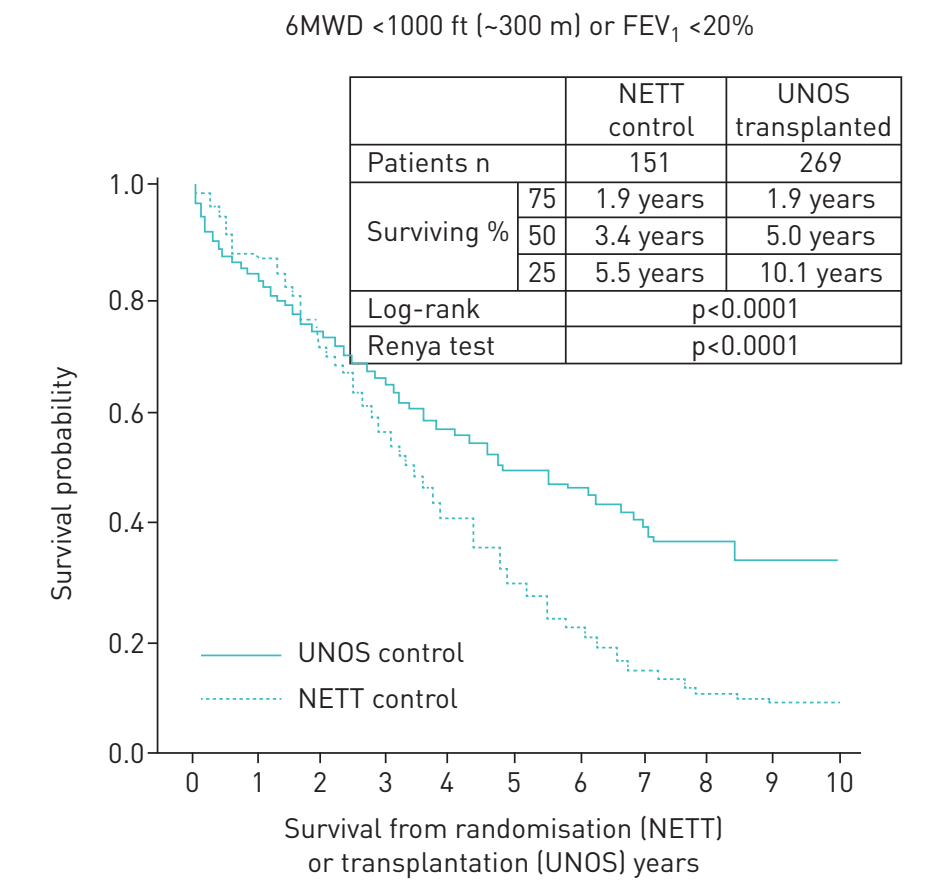

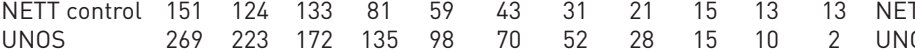

transplant

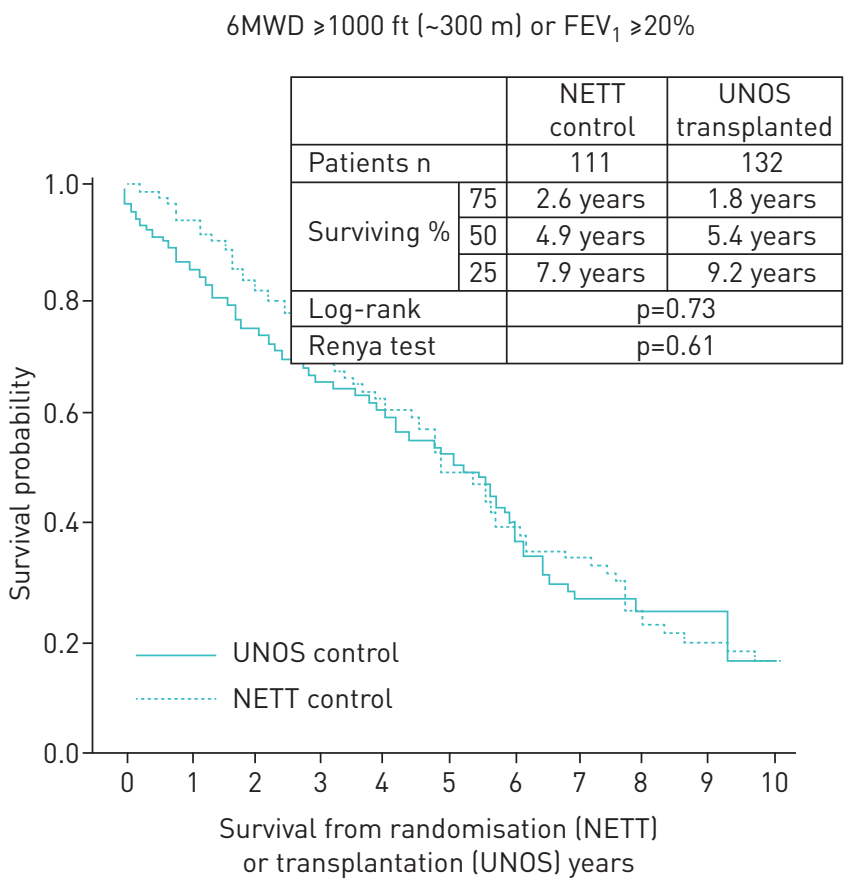

or transplantation (UNOS) years

Low 6MWD $(<1000 \mathrm{ft}(\sim 300 \mathrm{~m})$ or FEV $1<20 \%)$ Survival \%

\begin{tabular}{|c|c|c|c|c|c|c|c|c|c|c|}
\hline Year & 1 & 2 & 3 & 4 & 5 & 6 & 7 & 8 & 9 & 10 \\
\hline UNOS & 85 & 73 & 66 & 57 & 50 & 47 & 39 & 37 & 34 & 34 \\
\hline NETT & 87 & 74 & 56 & 42 & 30 & 22 & 15 & 11 & 9 & 9 \\
\hline
\end{tabular}

High 6MWD $\left(<1000 \mathrm{ft}(\sim 300 \mathrm{~m})\right.$ and $\left.\mathrm{FEV}_{1}<20 \%\right)$ Survival \%

\begin{tabular}{|c|c|c|c|c|c|c|c|c|c|c|}
\hline Year & 1 & 2 & 3 & 4 & 5 & 6 & 7 & 8 & 9 & 10 \\
\hline UNOS & 86 & 75 & 66 & 60 & 53 & 38 & 27 & 25 & 25 & 17 \\
\hline NETT & 95 & 87 & 77 & 69 & 56 & 44 & 38 & 25 & 22 & 17 \\
\hline
\end{tabular}

FIGURE 3 Kaplan-Meier plot of survival curves for propensity-matched United Network for Organ Sharing (UNOS) transplant patients and National Emphysema Treatment Trial (NETT) patients, within each disease severity stratum. FEV $_{1}$ : forced expiratory volume in $1 \mathrm{~s}$. 
The finding of survival benefit in patients with low $\mathrm{FEV}_{1}$ or $6 \mathrm{MWD}$ undergoing lung transplantation is not unique to the $<20 \%$ predicted $\mathrm{FEV}_{1}$ and $<1000 \mathrm{ft}(\sim 300 \mathrm{~m}) 6 \mathrm{MWD}$ demarcations, as we found the benefit is even stronger among more severe patients with $\mathrm{FEV}_{1}<15 \%$ predicted or $<800 \mathrm{ft}(\sim 240 \mathrm{~m})$ for the 6 MWD.

As shown in figure 4, there was little difference in post-transplant survival according to disease severity stratum. Among the 4496 transplanted UNOS patients: median survival was 5.5 years in the more severe stratum, compared with 5.7 years in the less severe stratum $(\mathrm{p}=0.77)$. The median (IQR) LAS differed by 1.2 units between patients in the more severe stratum (33.6 (32.6-35.4)) and the less severe stratum (32.4 (31.7-33.5)); $\mathrm{p}<0.0001$. The same trend was observed within the transplanted patients who were propensity-matched to NETT patients. The median (IQR) LAS differed by only 0.5 units between transplanted patients in the more severe stratum $(32.7(31.9-33.7))$ and the less severe stratum (32.2 (31.6-33.4)) indicating non-clinical significance for LAS but statistical significance; $\mathrm{p}<0.008$.

\section{Discussion}

COPD is one of the most common indications for lung transplantation [1,3], but there is a continuing controversy regarding the survival benefit of this intervention for COPD patients. Various studies have reported a clear impact on life expectancy after lung transplantation for idiopathic pulmonary fibrosis, cystic fibrosis and primary pulmonary hypertension [3, 22-25]; reports for COPD patients are inconsistent [26, 27].

A retrospective cohort study of 1997 patients transplanted in the UK demonstrated that transplantation confers survival benefit for patients with emphysema [25], results consistent with earlier European studies $[23,24]$. In contrast, HosENPUd et al. [28], in a 1998 study reviewing the outcomes of 1274 lung transplant candidates found mortality for COPD patients on the waiting list was low; post-transplantation survival did not exceed waiting-list survival during the 2-year follow-up. Thabut et al. [29] in 2008 used the UNOS transplant and waitlist data to estimate the survival impact of lung transplant and reported that patients with an $\mathrm{FEV}_{1}<16 \%$ of predicted will gain at least 1 year of survival after transplant. In these studies, mortality after lung transplant is compared to mortality of potential recipients with COPD on a lung transplant waiting list who are not operated or censored at the time of operation. Those analyses are subject to potential selection bias.

To clarify the survival benefit of lung transplantation for COPD patients without this selection bias, we analysed survival data from the UNOS Thoracic Registry and compared it to survival in the control group of NETT, an independent COPD population. Initially, we performed a survival comparison of all UNOS listed patients and the NETT control cohort, censoring UNOS listed patients at the time if transplantation,

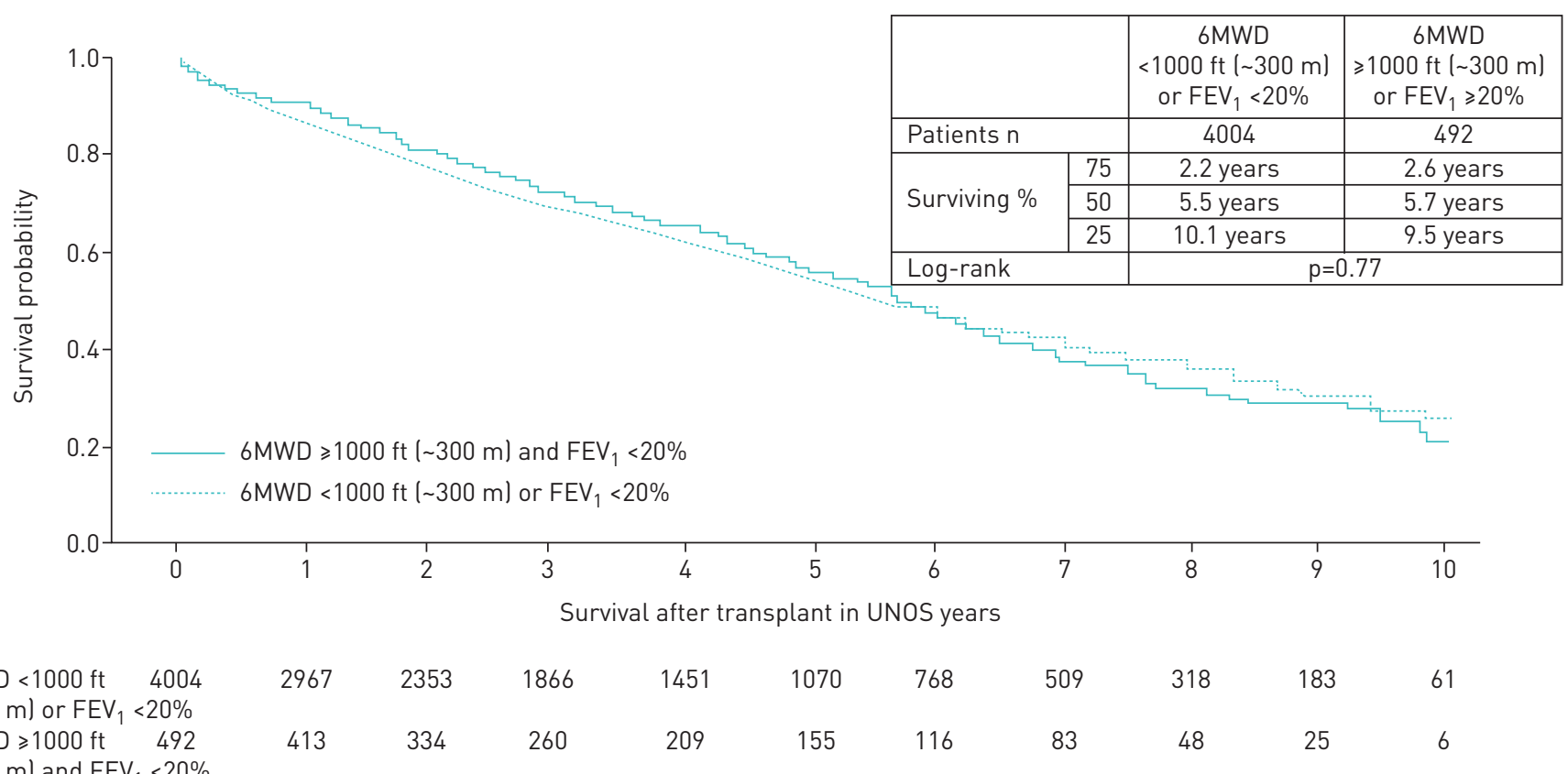

$6 \mathrm{MWD} \geqslant 1000 \mathrm{ft} \quad 492$

$(\sim 300 \mathrm{~m})$ and $\mathrm{FEV}_{1}<20 \%$ 
to establish that the two populations are comparable (5.2 years in NETT versus 4.7 years in UNOS). This analysis suggested that the populations of NETT and UNOS listed patients (censored at transplantation) are comparable for survival even though baseline characteristics indicated the NETT population was less severely ill; propensity score matched analysis seem reasonable.

Consistent with HosenPud et al. [28], in the first 2 years following transplantation or NETT randomisation, we found a similar survival in the UNOS (74\%) and NETT (77\%) groups, a difference that was not statistically significant $(\mathrm{p}=0.28)$. Patients undergoing lung transplantation experience immediate risks related to the procedure in exchange for the possibility of relief of symptoms and survival gains. The "crossing" NETT and UNOS survival curves are difficult to interpret and suggest both the possibility of long-term benefit and heterogeneity in the benefit of transplant. Therefore, we stratified patients according to disease severity as indicated by $6 \mathrm{MWD}$ and $\mathrm{FEV}_{1}$.

Although the curves cross still for the "more severe" stratum in the stratified analysis, they are closer together. There was a survival advantage for UNOS lung transplant patients compared to NETT patients among those with "more severe" COPD, as defined by $6 \mathrm{MWD}<1000 \mathrm{ft}(\sim 300 \mathrm{~m})$. or $\mathrm{FEV}_{1}<20 \%$ predicted. A large majority of transplanted patients in UNOS (89\%) were in the "more severe" category.

Less severely affected patients $\left(6 \mathrm{MWD} \geqslant 1000 \mathrm{ft}(\sim 300 \mathrm{~m})\right.$ and $\mathrm{FEV}_{1} \geqslant 20 \%$ of predicted), $11 \%$ of transplanted patients in UNOS, showed little if any increase in survival with lung transplantation. For these patients, on a case-by-case basis, there may be other clinical or functional reasons that suggest urgency of lung transplantation.

The difference in LAS scores between the "more severe" and "less severe" strata was small in spite of the clear difference in survival benefit of transplantation, suggesting that for COPD patients, the LAS score may not reflect post-transplant survival benefit. A composite index of clinical parameters able to predict post-transplant surgery survival is urgently needed.

There is a difference of a decade in the observation on NETT patients and the UNOS patients we report; but, COPD mortality and prognosis have not changed substantially in the last 3 decades. Specific therapies (like new inhalers or endobronchial valves placement) have had some impact on quality of life but none other than transplantation on survival [30].

UNOS does not contain quality of life information, and this outcome was not assessed in our study. Because UNOS does not quantify dyspnoea, we were not able to calculate the BODE (BMI, airflow obstruction, dyspnoea, exercise capacity) index for UNOS patients. However, the criteria of 6 MWD $<1000 \mathrm{ft}(\sim 300 \mathrm{~m})$ or $\mathrm{FEV}_{1}<20 \%$ of predicted are consistent with the recent International Society for Heart and Lung Transplantation (ISHLT) consensus that proposes a BODE threshold $\geqslant 7$, which represents a low $\mathrm{FEV}_{1}$ and $6 \mathrm{MWD}$, for transplant listing [28].

The study has limitations associated with the retrospective nature of the UNOS data. A considerable proportion of transplanted patients had to be excluded because they did not meet the NETT inclusion criteria; e.g. patients with low $6 \mathrm{MWD}(459 \mathrm{ft}(\sim 140 \mathrm{~m})$ ), severe pulmonary hypertension ( $>35 \mathrm{mmHg})$ or high oxygen requirements $\left(>6 \mathrm{~L} \cdot \mathrm{min}^{-1}\right)$. But our comparison in this limited population should generalise well because the more severely affected patients will almost surely benefit from surgery unless they are among the infrequent perioperative mortality cases and the less severely affected will do better than without surgery. Our results suggest that perioperative mortality is similar for the less severely affected COPD patients and the more severely affected patients who would sustain the most benefit from transplant.

Although the results could not be extended to all COPD patients listed for transplantation, our study suggests that more severe COPD cases are better candidates for lung transplantation when survival is the primary outcome measure not taking into account quality-of-life assessment. The retrospective nature of UNOS data does not allow quality-of-life assessment as this information is not recorded in UNOS database. A comparison of post-transplant survival between the more severe and less severe COPD patients indicated that post-transplant survival is similar regardless of disease severity among COPD patients, refuting the common argument that more severe patients are too high risk for transplantation with surgery increasing death risk in more ill patients. Differences in survival benefit between the disease severity strata are due to the favourable survival of less severely affected COPD patients even without transplantation treated with medical therapy and pulmonary rehabilitation according to NETT criteria. These results should be generalised with some caution because the NETT patients were selected to meet all enrollment criteria for that clinical trial.

\section{Conclusion}

We conclude that transplant surgery has a survival benefit in the more severely affected end-stage COPD patients (with $6 \mathrm{MWD}<1000 \mathrm{ft}(\sim 300 \mathrm{~m})$ or $\left.\mathrm{FEV}_{1}<20 \%\right)$, and, no appreciable benefit for the less severely 
affected patients. $6 \mathrm{MWD}$ and $\mathrm{FEV}_{1}$ contributes to the clinical decision-making process for pulmonologists and thoracic surgeons evaluating end-stage COPD patients.

Conflict of interest: I. Timofte has nothing to disclose. M. Wijesinha has nothing to disclose. R. Vesselinov has nothing to disclose. J. Kim has nothing to disclose. R. Reed reports grants from the Dept of Defense and the Flight Attendant Medical Research Institute during the conduct of the study; and grants from the National Institutes of Health, the COPD Foundation, Janssen Research \& Development LLC and the University of Maryland Institute for Clinical and Translational Research outside the submitted work. P.G. Sanchez has nothing to disclose. N. Ladikos has nothing to disclose. S. Pham has nothing to disclose. Z. Kon reports consulting and speaking fees from Medtronic, Inc., and consulting fees from Breethe, Inc., outside the submitted work. K. Rajagopal has nothing to disclose. S.M. Scharf has nothing to disclose. R. Wise reports grants, and personal fees for data monitoring committees and consulting from AstraZeneca, Medimmune, Pearl and Boehringer Ingelheim; personal fees for a clinical endpoint committee from Contrafect; personal fees for data safety monitoring committees from Pulmonx, Roche, Merck and AbbVie; personal fees for a steering committee from Spiration; personal fees for a workshop and consulting from Sunovion; research grants from Pearl Therapeutics and Sanofi-Aventis; personal fees for consultancy from Circassia, Pneuma, Verona, Mylan/Theravance and Propelleor Health; grants, and personal fees for a data monitoring committee, consultancy, a scientific advisory board and a clinical endpoint committee from GSK, outside the submitted work. A.L. Sternberg reports that the NETT was supported by contracts from the NHLBI during the conduct of the study. D. Kaczorowski has nothing to disclose. B. Griffith has nothing to disclose. M. Terrin has nothing to disclose. A. Iacono has nothing to disclose.

Support statement: The National Emphysema Treatment Trial was supported by the National Heart, Lung, and Blood Institute (N01HR76101， N01HR76102，N01HR76103，N01HR76104， N01HR76105，N01HR76106， N01HR76107, N01HR76108, N01HR76109, N01HR76110, N01HR76111, N01HR76112, N01HR76113, N01HR76114, N01HR76115, N01HR76116, N01HR76118, and N01HR76119), the Centers for Medicare and Medicaid Services, and the Agency for Healthcare Research and Quality. Funding information for this article has been deposited with the Crossref Funder Registry.

\section{References}

1 Chambers DC, Yusen RD, Cherikh WS, et al. The Registry of the International Society for Heart and Lung Transplantation: Thirty-fourth Adult Lung And Heart-Lung Transplantation Report-2017; Focus Theme: Allograft ischemic time. International Society for Heart and Lung Transplantation. J Heart Lung Transplant 2017; 36: 1047-1059, Epub 2017 Jul 19.

2 Aziz F, Penupolu S, Xu X, et al. Lung transplant in end-staged chronic obstructive pulmonary disease (COPD) patients: a concise review. J Thorac Dis 2010; 2: 111-116. PMID:22263028.

3 Anthonisen NR. Prognosis in chronic obstructive pulmonary disease: results from multicentre clinical trials. Am Rev Respir Dis 1989; 140: S95-S99.

4 Siddiqui FM, Diamond JM. Lung transplantation for chronic obstructive pulmonary disease: past, present, and future directions. Curr Opin Pulm Med 2018; 24: 199-204. PMID:29227305.

5 George MP, Champion HC, Pilewski JM. Lung transplantation for pulmonary hypertension. Pulm Circ 2011; 1 182-191. PMID:22034605.

6 Lipsi R, Mazzola D, Caminati A, et al. Severe idiopathic pulmonary fibrosis: A clinical approach. Eur J Intern Med 2018; 50: 20-27. pii: S0953-6205(18)30014-1. Review. PMID: 29361476.

7 Global Initiative for Chronic Obstructive Lung Disease. Global Strategy for the Diagnosis, Management and Prevention of Chronic Obstructive pulmonary disease: 2018 Report. www.goldcopd.org. Date last accessed: April $20,2018$.

8 Hoyert DL, Xu J. Deaths: Preliminary data for 2011. National Vital Statistics Reports; US Department of Health and Human Services, 2012.

9 Lozano R, Naghavi M, Foreman K, et al. Global and regional mortality from 235 causes of death for 20 age groups in 1990 and 2010: a systematic analysis for the Global Burden of Disease Study 2010. Lancet 2012; 380: 2095-2128.

10 Mathers CD, Loncar D. Projections of global mortality and burden of disease from 2002 to 2030. PLoS Med 2006; 3: e442.

11 Celli BR. Predictors of mortality in COPD. Respir Med 2010; 104: 773-779.

12 Traver GA, Cline MG, Burrows B. Predictors of mortality in chronic obstructive pulmonary disease. A 15-year follow-up study. Am Rev Respir Dis 1979; 119: 895-902.

13 Lane CR, Tonelli AR. Lung transplantation in chronic obstructive pulmonary disease: patient selection and special considerations. Int J Chron Obstruct Pulmon Dis 2015; 10: 2137-2146. eCollection 2015. Review. PMID:26491282.

14 Casanova C, Cote C, Marin JM, et al. Distance and oxygen desaturation during the 6-min walk test as predictors of long-term mortality in patients with COPD. Chest 2008; 134: 746-752.

15 Oga T, Nishimura K, Tsukino M, et al. Analysis of the factors related to mortality in chronic obstructive pulmonary disease: role of exercise capacity and health status. Am J Respir Crit Care Med 2003; 167: 544-549.

16 Celli BR, Cote CG, Marin JM, et al. The body-mass index, airflow obstruction, dyspnea, and exercise capacity index in chronic obstructive pulmonary disease. N Engl J Med 2004; 350: 1005-1012.

17 Division of Transplantation, Bureau of Health Resources Development. 2005 Annual Report of the US Scientific Registry for Transplant Recipients and the Organ Procurement and Transplantation Network - Transplant Data:1995-2004. Rockville, MD, Health Resources and Services Administration; US Department of Health and Human Services, 2005.

18 Gottlieb J. Lung allocation. J Thorac Dis 2017; 9: 2670-2674.

19 Fishman A, Martinez F, Naunheim K, et al. A randomized trial comparing lung-volume-reduction surgery with medical therapy for severe emphysema. N Engl J Med 2003; 348: 2059-2073. 
Weill D, Benden C, Corris PA, et al. A consensus document for the selection of lung transplant candidates: 2014--an update from the Pulmonary Transplantation Council of the International Society for Heart and Lung Transplantation. J Heart Lung Transplant 2015; 34: 1-15.

21 Celli B, Tetzlaff K, Criner G, et al. The 6-Minute-Walk Distance Test as a Chronic Obstructive Pulmonary Disease Stratification Tool. Insights from the COPD Biomarker Qualification Consortium. Am J Respir Crit Care Med 2016; 194: 1483-1493.

22 Hosenpud J, Bennett LE, Keck BM, et al. The Registry of the International Society for Heart and Lung Transplantation: seventeenth official report-2000. J Heart Lung Transplant 2000; 19: 909-931.

23 Charman SC, Sharples LD, McNeil KD, et al. Assessment of survival benefit after lung transplantation by patient diagnosis. J Heart Lung Transplant 2002; 21: 226-232.

24 De Meester J, Smits JM, Persijn GG, et al. Listing for lung transplantation: life expectancy and transplant effect, stratified by type of end-stage lung disease, the Eurotransplant experience. J Heart Lung Transplant 2001; 20: 518-524.

25 Thabut G, Mal H, Castier Y, et al. Survival benefit of lung transplantation for patients with idiopathic pulmonary fibrosis. J Thorac Cardiovasc Surg 2003; 126: 469-475.

26 Thabut G, Mal H. Outcomes after lung transplantation. J Thorac Dis 2017; 9: 2684-2691.

27 Titman A, Rogers CA, Bonser RS, et al. Disease-specific survival benefit of lung transplantation in adults: a national cohort study. Am J Transplant 2009; 9: 1640-1649.

28 Hosenpud J, Bennett LE, Keck BM, et al. Effect of diagnosis on survival benefit of lung transplantation for end-stage lung disease. Lancet 1998; 351: 24-27.

29 Thabut G, Ravaud P, Christie JD, et al. Determinants of the survival benefit of lung transplantation in patients with chronic obstructive pulmonary disease. Am J Respir Crit Care Med 2008; 177: 1156-1163.

30 Garner J, Kemp SV, Toma TP, et al. Survival after endobronchial valve placement for emphysema: a 10-year follow-up study. Am J Respir Crit Care Med 2016; 194: 519-521. 